\title{
A simulation study on the accuracy of position and effect estimates of linked QTL and their asymptotic standard deviations using multiple interval mapping in an $F_{2}$ scheme
}

\author{
Manfred MAYer $^{\mathrm{a} *}$, Yuefu Liu ${ }^{\mathrm{b}}$, Gertraude FrEYER $^{\mathrm{a}}$ \\ ${ }^{a}$ Research Unit Genetics and Biometry, Research Institute for the Biology of Farm Animals, \\ Dummerstorf, Germany \\ ${ }^{\mathrm{b}}$ Centre of the Genetic Improvement of Livestock, University of Guelph, Ontario, Canada
}

(Received 4 August 2003; accepted 22 March 2004)

\begin{abstract}
Approaches like multiple interval mapping using a multiple-QTL model for simultaneously mapping QTL can aid the identification of multiple QTL, improve the precision of estimating QTL positions and effects, and are able to identify patterns and individual elements of QTL epistasis. Because of the statistical problems in analytically deriving the standard errors and the distributional form of the estimates and because the use of resampling techniques is not feasible for several linked QTL, there is the need to perform large-scale simulation studies in order to evaluate the accuracy of multiple interval mapping for linked QTL and to assess confidence intervals based on the standard statistical theory. From our simulation study it can be concluded that in comparison with a monogenetic background a reliable and accurate estimation of QTL positions and QTL effects of multiple QTL in a linkage group requires much more information from the data. The reduction of the marker interval size from $10 \mathrm{cM}$ to $5 \mathrm{cM}$ led to a higher power in QTL detection and to a remarkable improvement of the QTL position as well as the QTL effect estimates. This is different from the findings for (single) interval mapping. The empirical standard deviations of the genetic effect estimates were generally large and they were the largest for the epistatic effects. These of the dominance effects were larger than those of the additive effects. The asymptotic standard deviation of the position estimates was not a good criterion for the accuracy of the position estimates and confidence intervals based on the standard statistical theory had a clearly smaller empirical coverage probability as compared to the nominal probability. Furthermore the asymptotic standard deviation of the additive, dominance and epistatic effects did not reflect the empirical standard deviations of the estimates very well, when the relative QTL variance was smaller/equal to 0.5 . The implications of the above findings are discussed.
\end{abstract}

mapping / QTL / simulation / asymptotic standard error / confidence interval

\footnotetext{
*Corresponding author: mmayer@fbn-dummerstorf.de
} 


\section{INTRODUCTION}

In their landmark paper Lander and Botstein [15] proposed a method that uses two adjacent markers to test for the existence of a quantitative trait locus (QTL) in the interval by performing a likelihood ratio test at many positions in the interval and to estimate the position and the effect of the QTL. This approach was termed interval mapping. It is well known however, that the existence of other QTL in the linkage group can distort the identification and quantification of QTL [10,11,15,31]. Therefore, QTL mapping combining interval mapping with multiple marker regression analysis was proposed $[11,30]$. The method of Jansen [11] is known as multiple QTL mapping and Zeng [31] named his approach composite interval mapping. Liu and Zeng [19] extended the composite interval mapping approach to mapping QTL from various cross designs of multiple inbred lines.

In the literature, numerous studies on the power of data designs and mapping strategies for single QTL models like interval mapping and composite interval mapping can be found. But these mapping methods often provide only point estimates of QTL positions and effects. To get an idea of the precision of a mapping study, it is important to compute the standard deviations of the estimates and to construct confidence intervals for the estimated QTL positions and effects. For interval mapping, Lander and Botstein [15] proposed to compute a lod support interval for the estimate of the QTL position. Darvasi et al. [7] derived the maximum likelihood estimates and the asymptotic variance-covariance matrix of QTL position and effects using the NewtonRaphson method. Mangin et al. [21] proposed a method to obtain confidence intervals for QTL location by fixing a putative QTL location and testing the hypothesis that there is no QTL between that location and either end of the chromosome. Visscher et al. [28] have suggested a confidence interval based on the unconditional distribution of the maximum-likelihood estimator, which they estimate by bootstrapping. Darvasi and Soller [6] proposed a simple method for calculating a confidence interval of QTL map location in a backcross or $\mathrm{F}_{2}$ design. For an 'infinite' number of markers (e.g., markers every $0.1 \mathrm{cM}$ ), the confidence interval corresponds to the resolving power of a given design, which can be computed by a simple expression including sample size and relative allele substitution effect. Lebreton and Visscher [17] tested several nonparametric bootstrap methods in order to obtain confidence intervals for QTL positions. Dupuis and Siegmund [9] discussed and compared three methods for the construction of a confidence region for the location of a QTL, namely support regions, likelihood methods for change points and Bayesian credible 
regions in the context of interval mapping. But all these authors did not address the complexities associated with multiple linked, possibly interacting, QTL.

Kao and Zeng [13] presented general formulas for deriving the maximum likelihood estimates of the positions and effects of QTL in a finite normal mixture model when the expectation maximization algorithm is used for QTL mapping. With these general formulas, QTL mapping analysis can be extended to the simultaneous use of multiple marker intervals in order to map multiple QTL, analyze QTL epistasis and estimate the QTL effects. This method was called multiple interval mapping by Kao et al. [14]. Kao and Zeng [13] showed how the asymptotic variance of the estimated effects can be derived and proposed to use standard statistical theory to calculate confidence intervals. In a small simulation study by Kao and Zeng [13] with just one QTL, however, it was of crucial importance to localize the QTL in the correct interval to make the asymptotic variance of the QTL position estimate reliable in QTL mapping. When the QTL was localized in the wrong interval, the sampling variance was underestimated. Furthermore, in the small simulation study of Kao and Zeng [13] with just one QTL, the asymptotic standard deviation of the QTL effect poorly estimated its empirical standard deviation. Nakamichi et al. [22] proposed a moment method as an alternative for multiple interval mapping models without epistatic effects in combination with the Akaike information criterion [1] for model selection, but their approach does not provide standard errors or confidence intervals for the estimates.

Because of the statistical problems in analytically deriving the standard errors and distribution of the estimates and because the use of resampling techniques like the ones described above for single or composite interval mapping methods does not seem feasible for several linked QTL, the need to perform large-scale simulation studies in order to evaluate the accuracy of multiple interval mapping for linked QTL is apparent. Therefore we performed a simulation study to assess the accuracy of position and effect estimates for multiple, linked and interacting QTL using multiple interval mapping in an $\mathrm{F}_{2}$ population and to examine the confidence intervals based on the standard statistical theory.

\section{MATERIALS AND METHODS}

\subsection{Genetic and statistical model of multiple interval mapping in an $\mathbf{F}_{2}$ population}

In an $\mathrm{F}_{2}$ population, an observation $y_{k}(k=1,2, \ldots, n)$ can be modeled as follows when additive genetic and dominance effects, and pairwise epistatic 
effects are considered:

$$
\begin{aligned}
y_{k}=\mathbf{x}_{k}^{\prime} \boldsymbol{\beta}+\sum_{i=1}^{m}\left(a_{i} x_{k i}+d_{i} z_{k i}\right)+\sum_{i=1}^{m-1} \sum_{j=i+1}^{m} \delta_{a_{i} a_{j}}\left(w_{a_{i} a_{j}} x_{k i} x_{k j}\right) \\
+\sum_{i=1}^{m-1} \sum_{j=i+1}^{m}\left[\delta_{a_{i} d_{j}}\left(w_{a_{i} d_{j}} x_{k i} z_{k j}\right)+\delta_{d_{i} a_{j}}\left(w_{d_{i} a_{j}} z_{k i} x_{k j}\right)\right] \\
+\sum_{i=1}^{m-1} \sum_{j=i+1}^{m} \delta_{d_{i} d_{j}}\left(w_{d_{i} d_{j}} z_{k i} z_{k j}\right)+e_{k}
\end{aligned}
$$

where

$x_{k i}=\left\{\begin{aligned} 1 & \text { if the QTL genotype is } Q_{i} Q_{i} \\ 0 & \text { if the QTL genotype is } Q_{i} q_{i} \\ -1 & \text { if the QTL genotype is } q_{i} q_{i}\end{aligned}\right.$

$$
\text { and } z_{k i}=\left\{\begin{aligned}
\frac{1}{2} & \text { if the QTL genotype is } Q_{i} q_{i} \\
-\frac{1}{2} & \text { otherwise. }
\end{aligned}\right.
$$

Here, $y_{k}$ is the observation of the $k$ th individual; $a_{i}$ and $d_{i}$ are the additive and dominance effects at putative QTL locus $i ; \delta_{a_{i} a_{j}}, \delta_{a_{i} d_{j}}, \delta_{d_{i} a_{j}}$ and $\delta_{d_{i} d_{j}}$ are epistatic interactions of additive by additive, additive by dominance, dominance by additive and dominance by dominance, respectively, between putative QTL loci $i$ and $j(i, j=1,2, \ldots m) . w_{a_{i} a_{j}}$ is an indicator variable and is equal to 1 if the epistatic interaction of additive by additive exists between putative QTL loci $i$ and $j$, and 0 otherwise; $w_{a_{i} d_{j}}, w_{a_{i} d_{j}}$ and $w_{a_{i} d_{j}}$ are defined in the corresponding way. $\boldsymbol{\beta}$ is the vector of fixed effects such as sex, age or other environmental factors. $\mathbf{x}_{k}$ is a vector, the $k$ th row of the design matrix $\mathrm{X}$ relating the fixed effects $\beta$ and observations. $e_{k}$ is the residual effect for observation $k$ and $e_{k} \sim \operatorname{NID}\left(0, \sigma^{2}\right)$.

This is an orthogonal partition of the genotypic effects in terms of genetic parameters, calculated according to Cockerham [5]. To avoid an overparameterization of the multiple interval model, a subset of the parameters of the above model can be used for modeling the observations. 
For the analyses, a computer program that was based on an initial version of a multiple interval mapping program mentioned in Kao et al. [14] was used. Comprehensive modifications in the original program were made to meet the needs of this study.

\subsection{Simulation model}

Two different model types were used to simulate the data. In the parental generation, inbred lines with homozygous markers and QTL were postulated. In the first model, we assumed three QTL in a linkage group of $200 \mathrm{cM}$. The positions of the QTL were set to 55, 135 and $155 \mathrm{cM}$; i.e., the first QTL was relatively far away from the other two QTL, whereas the QTL two and three were in a relatively close neighborhood. The three QTL all had the same additive effects $\left(a_{1}=a_{2}=a_{3}=1\right)$ and showed no dominance or epistatic effects. The residuals were scaled to give the variance explained by the QTL in an $\mathrm{F}_{2}$ population to be 0.25 (model 1a), 0.50 (model 1b) and 0.75 (model 1c), respectively. This was done to study the influence of the magnitude of the relative QTL variance on the results. The genotypic values of the individuals in all three data sets were identical. In each replicate, an $\mathrm{F}_{2}$ population with a sample size of 500 was generated and one hundred replicates were simulated.

In the second simulation model the same QTL positions were assumed. But we included an epistatic interaction in the simulation, because a major advantage of multiple interval mapping is its ability to analyze gene interactions. In addition to equal additive effects of the three QTL, a partial dominance effect at QTL position 3 and an epistatic interaction of additive by additive effects between QTL loci 1 and 2 were simulated. Setting the additive effects equal to one $\left(a_{1}=a_{2}=a_{3}=1\right)$, the dominance effect was $d_{3}=0.5$ and the epistatic effect $\delta_{a_{1} a_{2}}=-3$. Thus, the genotypic values expressed as the deviation from the general mean were $-1,1,3,1,0,-1,3,-1$ and -5 for the 9 genotypes Q1Q1Q2Q2, Q1Q1Q2q2, Q1Q1q2q2, Q1q1Q2Q2, Q1q1Q2q2, Q1q1q2q2, q1q1Q2Q2, q1q1Q2q2 and q1q1q2q2, respectively plus $0.75,0.25$, -1.25 for the genotypes $\mathrm{Q}_{3} \mathrm{Q}_{3}, \mathrm{Q}_{3} \mathrm{q}_{3}$ and $\mathrm{q}_{3} \mathrm{q}_{3}$, respectively. Again, the residuals were scaled to give a QTL variance in the $\mathrm{F}_{2}$ population of 0.25 (model $2 \mathrm{a}$ ), 0.50 (model 2b) and 0.75 (model 2c), respectively.

The markers were evenly distributed in the linkage group with an interval size of $5 \mathrm{cM}(0,5, \ldots, 200 \mathrm{cM})$. However, it was assumed that no marker was available directly at the QTL positions $(55,135,155 \mathrm{cM})$ but at the positions $52.5,57.5,132.5,137.5,152.5$ and $157.5 \mathrm{cM}$ instead. To analyze the influence of the marker interval size on the estimates of QTL positions and effects, 
the same data sets were reanalyzed using the marker information on the positions $0,10,20, \ldots, 200 \mathrm{cM}$ only, i.e., with a marker interval size of $10 \mathrm{cM}$.

\subsection{Data analysis}

The likelihood of the multiple interval mapping model is a finite normal mixture. Kao and Zeng [13] proposed general formulas in order to obtain the maximum likelihood estimators using an expectation-maximization (EM) algorithm [8, 18]. In accordance with Zeng et al. [32], we found that for numerical stability and convergence of the algorithm it is important in the M-step not to update the parameter blockwise as stated in the original paper of Kao and Zeng [13], but to update the parameters one by one and to use all new estimates immediately.

In this study a multidimensional complete grid search on the likelihood surface was performed. This is computationally very expensive and was done for two reasons. The first aim was to get an idea about the likelihood landscape. Secondly, it should be ensured that really the global maximum of the likelihood function was found. The search for the QTL was performed at $5 \mathrm{cM}$ intervals for each replicate. In the regions around the QTL, i.e., from 50 to $60 \mathrm{cM}, 130$ to $140 \mathrm{cM}$ and 150 to $160 \mathrm{cM}$, respectively the search interval was set to $1 \mathrm{cM}$. The multiple interval mapping model analyzing the simulated data of model 1 included a general mean, the error term and additive effects of the putative QTL. The model analyzing the data from the second simulation included additive and dominance effects for all QTL and pairwise additive by additive epistatic interactions among all QTL in the model.

\subsection{QTL detection}

For QTL detection and model selection with the multiple interval model Kao et al. [14] recommended using a stepwise selection procedure and the likelihood ratio test statistic for adding (or dropping) QTL parameters. They suggest using the Bonferroni argument to determine the critical value for claiming QTL detection. Nakamichi et al. [22] strongly advocate using the Akaike information criterion [1] in model selection. They argue that the Akaike information criterion maximizes the predictive power of a model and thus creates a balance of type I and type II errors. Basten et al. [2] recommend in their QTL Cartographer manual to use the Bayesian information criterion [25]. An information criterion in the general form is based on minimizing $-2\left(\log L_{k}-k c(n) / 2\right)$, where $L_{k}$ is the likelihood of data given a model with $k$ parameters and $c(n)$ is 
a penalty function. Thus, the information criteria can easily be related to the use of likelihood ratio-test statistics and threshold values for the selection of variables. An in-depth discussion on model selection issues with the multiple interval model, on information criteria and stopping rules can be found in Zeng et al. [32].

QTL detection means that at least one of the genetic effects of a QTL is not zero. In this study we present the results from the use of several information criteria, viz. the Akaike information criterion (AIC), Bayesian information criterion (BIC) and the likelihood ratio test statistic (LRT) in combination with a threshold based on the Bonferroni argument for QTL detection as proposed by Kao et al. [14]. In QTL detection, we compared the information criterion of an $(m-1)$-QTL model with all the parameters in the class of models considered with the information criterion of a model including the same parameters plus an additional parameter for the $m$-QTL model. Thus, the penalty functions used were $c(n)=2$ based on AIC and $c(n)=\log (n)=\log (500) \approx 6.2146$ based on BIC, respectively. The threshold value for the likelihood ratio test statistic was $\chi_{(1,0.05 / 20)}^{2} \approx 9.1412$ (marker interval $10 \mathrm{cM}$ ) and $\chi_{(1,0.05 / 40)}^{2} \approx 10.4167$ (marker interval $5 \mathrm{cM}$ ), respectively. This is equivalent to using $c(n)=9.1412$ and 10.4167 , respectively and a threshold value of 0 . Since model 1 included additive genetic effects, but no dominance or epistatic effects this is a stepwise selection procedure to identify the number of QTL $(m=1, \ldots, 3)$ based on the mentioned criteria. For model 2, this approach means in the maximum likelihood context that the hypothesis is split into subsets of hypotheses and a union intersection method [4] is used for testing the $m$-QTL model. Each subset of hypotheses tests one of the additional parameters. If all the subsets of the null hypothesis are not rejected based on the separate tests, the null hypothesis will not be rejected. The rejection of any subset of the null hypothesis will lead to the rejection of the null hypothesis. In comparison with strategies based on information criteria and allowing the chunkwise consideration of additional parameters this approach tends to be slightly more conservative.

\subsection{Asymptotic variance-covariance matrix of the estimates}

The EM algorithm described above gives only point estimates of the parameters. To obtain the asymptotic variance-covariance matrix of the estimates, an approach described by Louis [20] as proposed by Kao and Zeng [13] was used. Louis [20] showed that when the EM algorithm is used, the observed information $I_{\mathrm{obs}}$ is the difference of complete $I_{\mathrm{oc}}$ and missing $I_{\mathrm{om}}$ information, i.e., $I_{\mathrm{obs}}\left(\boldsymbol{\theta}^{*} \mid \mathbf{Y}_{\mathrm{obs}}\right)=I_{\mathrm{oc}}-I_{\mathrm{om}}$, where $\theta^{*}$ denotes the maximum likelihood 
estimate of the parameter vector. The structure of the complete and missing information matrices are described by Kao and Zeng [13]. The inverse of the observed information matrix gives the asymptotic variance-covariance matrix of the parameters.

By this approach, if the estimated QTL position is right on the marker, there is no position parameter in the model and therefore its asymptotic variance cannot be calculated. Thus, when the maximum likelihood estimate of a QTL position was on a marker position we used an adjacent QTL position $1 \mathrm{cM}$ in direction towards the true QTL position to calculate the asymptotic variancecovariance matrix of the parameters.

\section{RESULTS}

\subsection{QTL detection}

The number of replicates where 3 QTL were detected depends on the criterion used. As can be seen from Table I, when the Akaike information criterion was used in all the replicates, with only one exception (relative QTL variance 0.25 , marker distance $10 \mathrm{cM}$, model 1), 3 QTL were identified. Also, the use of the Bayesian information criterion resulted in rather high detection rates. The power of QTL detection was $100 \%$ or was almost $100 \%$ when the relative QTL variances was equal to or greater than 0.50 using the Bonferroni argument, the most stringent criterion among the ones studied. For the relative QTL variance of 0.25 the detection rate ranged from $44 \%$ to $56 \%$. Comparing the marker distances of $10 \mathrm{cM}$ and $5 \mathrm{cM}$, the reduction of the marker interval size from $10 \mathrm{cM}$ to $5 \mathrm{cM}$ led to a clearly higher power in QTL detection.

\subsection{Position estimates in model 1}

Means and empirical standard deviations of the QTL position estimates for model 1 are shown in Table II for all the 100 replicates (a) and for the replicates that resulted in 3 identified QTL (s) using the most stringent criterion (Bonferroni argument). The QTL are labeled in the order of the estimated QTL position.

The mean position estimates were close to the true values except for the model with a relative QTL variance of 0.25 and a marker interval size of $10 \mathrm{cM}$. As can be seen from Figure 1 this is due to the fact, that in this case in a number of repetitions the position estimates were very inaccurate. This inaccuracy is also reflected by the high standard deviations of the QTL position 
Table I. Number of replicates (out of 100) where 3 QTL were detected in dependence on the information criterion ( $\mathrm{R}^{2}$ : relative $\mathrm{QTL}$ variance).

\begin{tabular}{|c|c|c|c|c|}
\hline \multirow[b]{2}{*}{$\mathrm{R}^{2}$} & \multirow{2}{*}{$\begin{array}{l}\text { Marker- } \\
\text { interval }\end{array}$} & \multicolumn{3}{|c|}{ Information criterion } \\
\hline & & AIC & $\mathrm{BIC}$ & $\begin{array}{r}\text { Bonferroni } \\
\text { argument }\end{array}$ \\
\hline \multicolumn{5}{|c|}{ model 1} \\
\hline 0.25 & $10 \mathrm{cM}$ & 99 & 67 & 44 \\
\hline 0.25 & $5 \mathrm{cM}$ & 100 & 88 & 56 \\
\hline 0.50 & $10 \mathrm{cM}$ & 100 & 100 & 100 \\
\hline 0.50 & $5 \mathrm{cM}$ & 100 & 100 & 100 \\
\hline 0.75 & $10 \mathrm{cM}$ & 100 & 100 & 100 \\
\hline 0.75 & $5 \mathrm{cM}$ & 100 & 100 & 100 \\
\hline \multicolumn{5}{|c|}{ model 2} \\
\hline 0.25 & $10 \mathrm{cM}$ & 100 & 77 & 45 \\
\hline 0.25 & $5 \mathrm{cM}$ & 100 & 91 & 53 \\
\hline 0.50 & $10 \mathrm{cM}$ & 100 & 100 & 93 \\
\hline 0.50 & $5 \mathrm{cM}$ & 100 & 100 & 96 \\
\hline 0.75 & $10 \mathrm{cM}$ & 100 & 100 & 100 \\
\hline 0.75 & $5 \mathrm{cM}$ & 100 & 100 & 100 \\
\hline
\end{tabular}

AIC: Akaike information criterion; BIC: Bayesian information criterion.

estimates (Tab. II). In general, the variances of the QTL position estimates decreased when increasing the marker density from $10 \mathrm{cM}$ to $5 \mathrm{cM}$. This tendency might have been expected, but the magnitude is quite remarkable.

For model 1 and a relative QTL variance of 0.25 , Figure 1 shows the distribution of the QTL position estimates in $5 \mathrm{cM}$ interval classes, where the estimates were rounded to the nearest $5 \mathrm{cM}$ value. In the case of all replicates and a marker interval size of $10 \mathrm{cM}$ only 28,34 and 28 , respectively out of the 100 estimates for the 3 QTL positions were within the correct $5 \mathrm{cM}$ interval. With a marker interval size of $5 \mathrm{cM}$, these values increased significantly to 62 , 61 and 57, respectively. Under further inclusion of the neighboring $5 \mathrm{cM}$ intervals the corresponding values were 67, 51, 57 (marker interval $10 \mathrm{cM}$ ) and 90, 87,88 (marker interval $5 \mathrm{cM}$ ). When the relative QTL variance was 0.50 the number of estimates in the correct $5 \mathrm{cM}$ class were 77,79 and 71 for a marker distance of $10 \mathrm{cM}$ compared to 89,88 and 86 for a marker distance of $5 \mathrm{cM}$ (Fig. 2). 
Table II. Means and empirical standard deviations of QTL position estimates (in cM) of simulation models 1 and 2 and means and standard deviations of the estimated asymptotic standard deviation $\left(\mathrm{R}^{2}\right.$ : relative QTL variance; a: all replicates $(N=100)$; $\mathrm{s}$ : based on the most stringent criterion (Bonferroni argument); no. of replicates see Tab. I).

\begin{tabular}{|c|c|c|c|c|c|c|c|c|c|}
\hline & \multirow[t]{2}{*}{$\mathrm{R}^{2}$} & \multirow{2}{*}{$\begin{array}{l}\text { Marker- } \\
\text { interval }\end{array}$} & & \multicolumn{3}{|c|}{ Model 1} & \multicolumn{3}{|c|}{ Model 2} \\
\hline & & & & QTL1 & QTL2 & QTL3 & QTL1 & QTL2 & QTL3 \\
\hline \multirow{11}{*}{$\begin{array}{l}\text { True value } \\
\text { mean }\end{array}$} & & & & 55 & 135 & 155 & 55 & 135 & 155 \\
\hline & 0.25 & $10 \mathrm{cM}$ & $\mathrm{a}$ & 49.6 & 124.0 & 158.9 & 53.1 & 122.9 & 155.7 \\
\hline & 0.25 & $10 \mathrm{cM}$ & $\mathrm{s}$ & 51.6 & 133.6 & 158.7 & 53.5 & 128.0 & 156.5 \\
\hline & 0.25 & $5 \mathrm{cM}$ & $\mathrm{a}$ & 55.0 & 131.7 & 155.7 & 54.9 & 130.3 & 155.8 \\
\hline & 0.25 & $5 \mathrm{cM}$ & s & 55.3 & 133.8 & 157.1 & 55.1 & 130.3 & 156.6 \\
\hline & 0.50 & $10 \mathrm{cM}$ & $\mathrm{a}$ & 54.4 & 134.7 & 155.5 & 54.7 & 134.7 & 155.2 \\
\hline & 0.50 & $10 \mathrm{cM}$ & $\mathrm{s}$ & 54.4 & 134.7 & 155.5 & 54.7 & 134.6 & 155.2 \\
\hline & 0.50 & $5 \mathrm{cM}$ & a & 55.2 & 134.1 & 154.7 & 55.4 & 134.5 & 154.5 \\
\hline & 0.50 & $5 \mathrm{cM}$ & $\mathrm{s}$ & 55.2 & 134.1 & 154.7 & 55.4 & 134.5 & 154.6 \\
\hline & 0.75 & $10 \mathrm{cM}$ & $\mathrm{a}, \mathrm{s}$ & 54.7 & 134.8 & 154.6 & 54.8 & 134.9 & 154.5 \\
\hline & 0.75 & $5 \mathrm{cM}$ & $\mathrm{a}, \mathrm{s}$ & 55.4 & 134.4 & 154.5 & 55.5 & 134.5 & 154.3 \\
\hline \multirow[t]{10}{*}{ SD } & 0.25 & $10 \mathrm{cM}$ & a & 14.99 & 29.54 & 13.17 & 8.30 & 25.24 & 13.38 \\
\hline & 0.25 & $10 \mathrm{cM}$ & s & 9.92 & 15.22 & 10.07 & 8.47 & 18.84 & 11.68 \\
\hline & 0.25 & $5 \mathrm{cM}$ & $\mathrm{a}$ & 4.96 & 11.96 & 6.91 & 3.00 & 16.00 & 11.58 \\
\hline & 0.25 & $5 \mathrm{cM}$ & $\mathrm{s}$ & 4.10 & 4.48 & 6.60 & 2.46 & 16.11 & 10.56 \\
\hline & 0.50 & $10 \mathrm{cM}$ & $\mathrm{a}$ & 2.89 & 3.31 & 3.74 & 1.41 & 1.82 & 5.61 \\
\hline & 0.50 & $10 \mathrm{cM}$ & s & 2.89 & 3.31 & 3.74 & 1.37 & 1.87 & 5.66 \\
\hline & 0.50 & $5 \mathrm{cM}$ & $\mathrm{a}$ & 2.04 & 2.29 & 2.54 & 0.97 & 0.97 & 3.95 \\
\hline & 0.50 & $5 \mathrm{cM}$ & $\mathrm{s}$ & 2.04 & 2.29 & 2.54 & 0.88 & 0.98 & 4.06 \\
\hline & 0.75 & $10 \mathrm{cM}$ & $\mathrm{a}, \mathrm{s}$ & 1.30 & 1.51 & 1.25 & 1.09 & 1.03 & 1.66 \\
\hline & 0.75 & $5 \mathrm{cM}$ & $\mathrm{a}, \mathrm{s}$ & 1.01 & 0.88 & 0.88 & 0.69 & 0.67 & 1.49 \\
\hline \multirow{10}{*}{$\begin{array}{l}\text { Mean of estim. } \\
\text { asymp. SD }\end{array}$} & 0.25 & $10 \mathrm{cM}$ & $\mathrm{a}$ & 3.39 & 3.14 & 3.85 & 1.96 & 2.43 & 3.33 \\
\hline & 0.25 & $10 \mathrm{cM}$ & $\mathrm{s}$ & 3.26 & 2.82 & 3.55 & 1.86 & 2.42 & 3.40 \\
\hline & 0.25 & $5 \mathrm{cM}$ & $\mathrm{a}$ & 3.36 & 4.32 & 4.49 & 2.57 & 2.89 & 4.66 \\
\hline & 0.25 & $5 \mathrm{cM}$ & $\mathrm{s}$ & 3.10 & 3.77 & 4.47 & 2.55 & 2.84 & 4.28 \\
\hline & 0.50 & $10 \mathrm{cM}$ & $\mathrm{a}$ & 1.87 & 2.16 & 2.22 & 1.28 & 1.43 & 2.57 \\
\hline & 0.50 & $10 \mathrm{cM}$ & $\mathrm{s}$ & 1.87 & 2.16 & 2.22 & 1.28 & 1.41 & 2.41 \\
\hline & 0.50 & $5 \mathrm{cM}$ & $\mathrm{a}$ & 2.35 & 2.72 & 2.54 & 1.72 & 1.85 & 3.40 \\
\hline & 0.50 & $5 \mathrm{cM}$ & $\mathrm{s}$ & 2.35 & 2.72 & 2.54 & 1.69 & 1.85 & 3.32 \\
\hline & 0.75 & $10 \mathrm{cM}$ & $\mathrm{a}, \mathrm{s}$ & 1.14 & 1.26 & 1.21 & 0.90 & 0.93 & 1.57 \\
\hline & 0.75 & $5 \mathrm{cM}$ & $\mathrm{a}, \mathrm{s}$ & 1.49 & 1.54 & 1.54 & 1.18 & 1.20 & 20.8 \\
\hline \multirow{10}{*}{$\begin{array}{l}\text { SD of estim. } \\
\text { asymp. SD }\end{array}$} & 0.25 & $10 \mathrm{cM}$ & $\mathrm{a}$ & 1.99 & 2.38 & 2.85 & 0.66 & 1.75 & 2.30 \\
\hline & 0.25 & $10 \mathrm{cM}$ & $\mathrm{s}$ & 1.14 & 1.21 & 1.51 & 0.51 & 1.63 & 2.77 \\
\hline & 0.25 & $5 \mathrm{cM}$ & $\mathrm{a}$ & 2.89 & 2.84 & 3.16 & 0.81 & 1.55 & 3.37 \\
\hline & 0.25 & $5 \mathrm{cM}$ & s & 2.75 & 1.66 & 2.20 & 0.85 & 1.40 & 2.49 \\
\hline & 0.50 & $10 \mathrm{cM}$ & a & 0.47 & 1.21 & 0.89 & 0.18 & 0.46 & 1.10 \\
\hline & 0.50 & $10 \mathrm{cM}$ & $\mathrm{s}$ & 0.47 & 1.21 & 0.89 & 0.18 & 0.36 & 0.86 \\
\hline & 0.50 & $5 \mathrm{cM}$ & $\mathrm{a}$ & 1.31 & 1.18 & 0.95 & 0.53 & 0.56 & 1.57 \\
\hline & 0.50 & $5 \mathrm{cM}$ & $\mathrm{s}$ & 1.31 & 1.18 & 0.95 & 0.49 & 0.56 & 1.42 \\
\hline & 0.75 & $10 \mathrm{cM}$ & $\mathrm{a}, \mathrm{s}$ & 0.18 & 0.32 & 0.29 & 0.13 & 0.14 & 0.36 \\
\hline & 0.75 & $5 \mathrm{cM}$ & $\mathrm{a}, \mathrm{s}$ & 0.58 & 0.48 & 0.75 & 0.21 & 0.25 & 0.74 \\
\hline
\end{tabular}



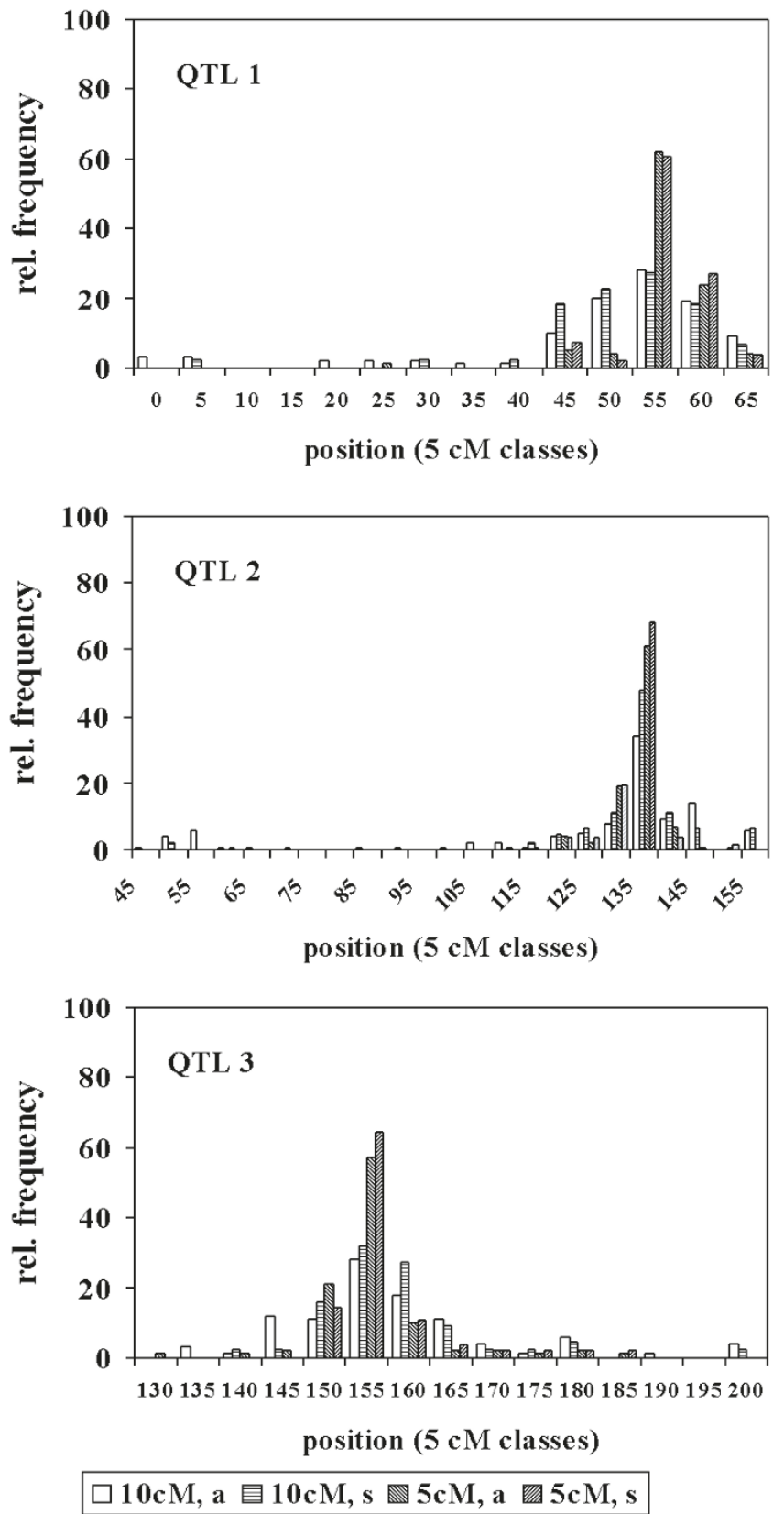

Figure 1. Distribution of the QTL position estimates for model 1 (rounded to the nearest $5 \mathrm{cM}$ value) and a relative QTL variance of 0.25 (a: all replicates $(N=100)$; $\mathrm{s}$ : based on the most stringent criterion (Bonferroni argument); no. of replicates see Tab. I). 

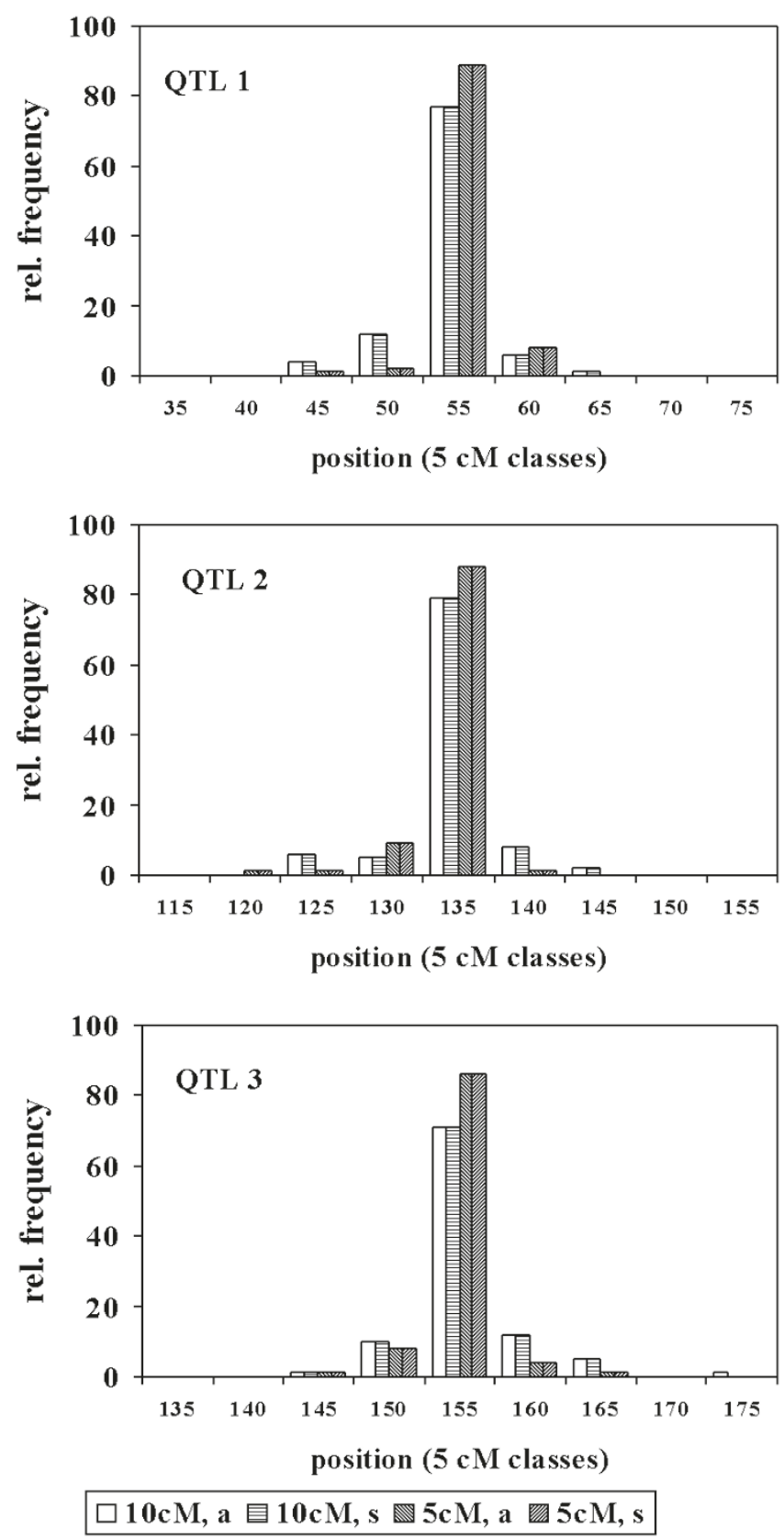

Figure 2. Distribution of the QTL position estimates for model 1 (rounded to the nearest $5 \mathrm{cM}$ value) and a relative QTL variance of 0.5 (a: all replicates $(N=100)$; $\mathrm{s}$ : based on the most stringent criterion (Bonferroni argument); no. of replicates see Tab. I). 
Although there was a substantial reduction in a few situations in the empirical standard deviations of the position estimates from the "significant" 3-QTLmodels using the most stringent threshold values, the standard errors were still rather large as can be seen from Table II and Figure 1.

For the relative QTL variance of 0.25 we measured the mean difference between the QTL position estimates from the 2 marker interval sizes as $m d=\frac{1}{3} \sum_{i=1}^{3}\left|a_{i}^{(5)}-a_{i}^{(10)}\right|$, where $a_{i}^{(5)}$ and $a_{i}^{(10)}$ are the position estimates for the $i$ th QTL and the marker distance of 5 and $10 \mathrm{cM}$, respectively. It turned out that in a large number of replicates, namely 61 out of the 100 replicates, the mean difference in the position estimates were smaller/equal to $5 \mathrm{cM}$ and in 45 replicates smaller/equal to $3 \mathrm{cM}$. In 50 out of the 55 cases where $m d$ was greater than $3 \mathrm{cM}$, the mean difference between the position estimates and the true position was smaller for the estimates from a marker distance of $5 \mathrm{cM}$ as compared to a marker distance of $10 \mathrm{cM}$. For the replicates with the largest values of $m d$ it was found that the likelihood surface often showed several local maxima of almost equal likelihood values when the marker distance was $10 \mathrm{cM}$. In these cases, often 2 of the 3 QTL were more or less correctly localized whereas the position estimate of the third QTL was very imprecise and the accuracy of the position estimates could be greatly improved by reducing the marker interval size from $10 \mathrm{cM}$ to $5 \mathrm{cM}$. The denser marker map also clearly tended to give estimates with larger likelihood-ratio test statistics.

Regarding first the situation with a marker interval size of $10 \mathrm{cM}$, the means of the estimated asymptotic standard deviations were clearly smaller than the respective empirical standard deviations. For the cases with a relative QTL variance of 0.25 and considering all replicates, the means of the estimated asymptotic standard deviation were 4.42, 9.41 and 3.42 times as large as the empirical standard deviation for QTL 1, QTL 2 and QTL 3, respectively. The respective factors for the relative QTL variance of 0.50 were $1.55,1.53$ and 1.68 for the 3 QTL. When using the denser marker map of $5 \mathrm{cM}$, the asymptotic standard deviations were still too small for the small effect QTL. It could be observed that when the QTL position estimates were close to the markers, the estimated asymptotic variance was sensitive to slight modifications in the positions used for the calculations.

Using the asymptotic statistical theory for each repetition, an asymptotic $95 \%$-confidence interval of the form estimate $\pm 1.96 *$ asymptotic standard deviation of the estimate can be computed. Then for all the repetitions it can be checked whether the true parameter lies within that interval giving the empirical coverage probability. As expected from the figures in Table II, it can 
be seen in Table $\mathrm{V}$ that the empirical coverage probability is much smaller than the nominal confidence interval, especially when the relative QTL variance was 0.25 and 0.50 , respectively. The mean and standard deviation of the size of the confidence intervals can be computed from the results given in Table II. Especially for the scenarios with a low relative QTL variance, they are, despite the low coverage probability, rather large. So for example, for the relative QTL variance, of 0.25 , a marker interval size of $10 \mathrm{cM}$ and based on the most stringent QTL detection threshold (Bonferroni argument) the average size \pm standard deviation (in $\mathrm{cM}$ ) of the estimated 95\%-confidence interval was $12.80 \pm 4.47,11.06 \pm 4.76,13.92 \pm 5.91(\mathrm{QTL} 1$, QTL 2 and QTL 3, respectively).

\subsection{Position estimates in model 2}

As compared to the results of model 1, the mean position estimates were almost in accordance with the true values except for the model with a relative QTL variance of 0.25 and a marker interval size of $10 \mathrm{cM}$ (Tab. II). Again the increase of the marker density from $10 \mathrm{cM}$ to $5 \mathrm{cM}$ leads to a clear reduction in the empirical standard deviations of the QTL position estimates. In comparison with model 1 the position estimates were more accurate for QTL 1 and QTL 2 and less accurate for QTL 3. This is also reflected by the distribution of the QTL position estimates in Figure 3 (a relative QTL variance of 0.25) and Figure 4 (a relative QTL variance of 0.50 ). Obviously the epistatic component between QTL 1 and QTL 2 had an influence on the accuracy of position estimation. With a relative QTL variance of 0.25 and a marker distance of $10 \mathrm{cM}$, only 23 out of the 100 position estimates for QTL 3 were within the correct $5 \mathrm{cM}$ interval. This percentage increased to 40 when the marker interval size was $5 \mathrm{cM}$. The respective values for QTL positions 1 and 2 are 74 and 52 (marker distance $10 \mathrm{cM}$ ), respectively which increased to 88 and 71 (marker distance $5 \mathrm{cM}$ ), respectively. In the case of the relative QTL variance of 0.50 the percentage of estimates in the correct $5 \mathrm{cM}$ interval increased from 56 to 75 for QTL 3 and from 92 and 90 to 98 for QTL 1 and QTL 2, respectively.

The means of the estimated asymptotic standard deviations of the position estimates were again smaller than the empirical standard deviations when the marker density was $10 \mathrm{cM}$ and in comparison showed somewhat larger means and variations when the marker density was $5 \mathrm{cM}$. The consequences for the coverage probabilities are shown in Table $\mathrm{V}$. 

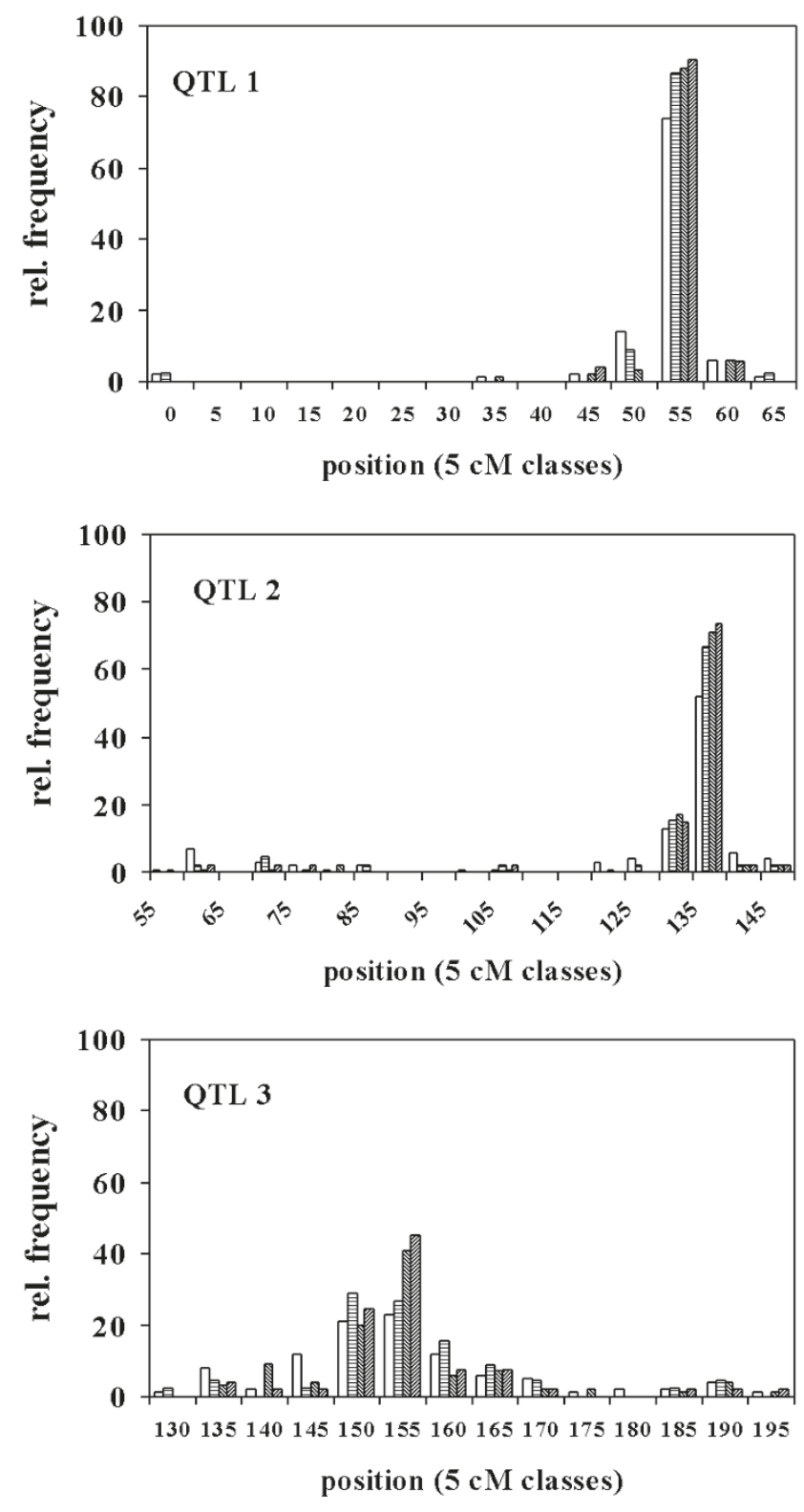

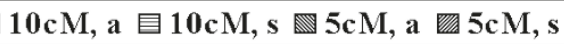

Figure 3. Distribution of the QTL position estimates for model 2 (rounded to the nearest $5 \mathrm{cM}$ value) and a relative QTL variance of 0.25 (a: all replicates $(N=100)$; $\mathrm{s}$ : based on the most stringent criterion (Bonferroni argument); no. of replicates see Tab. I). 

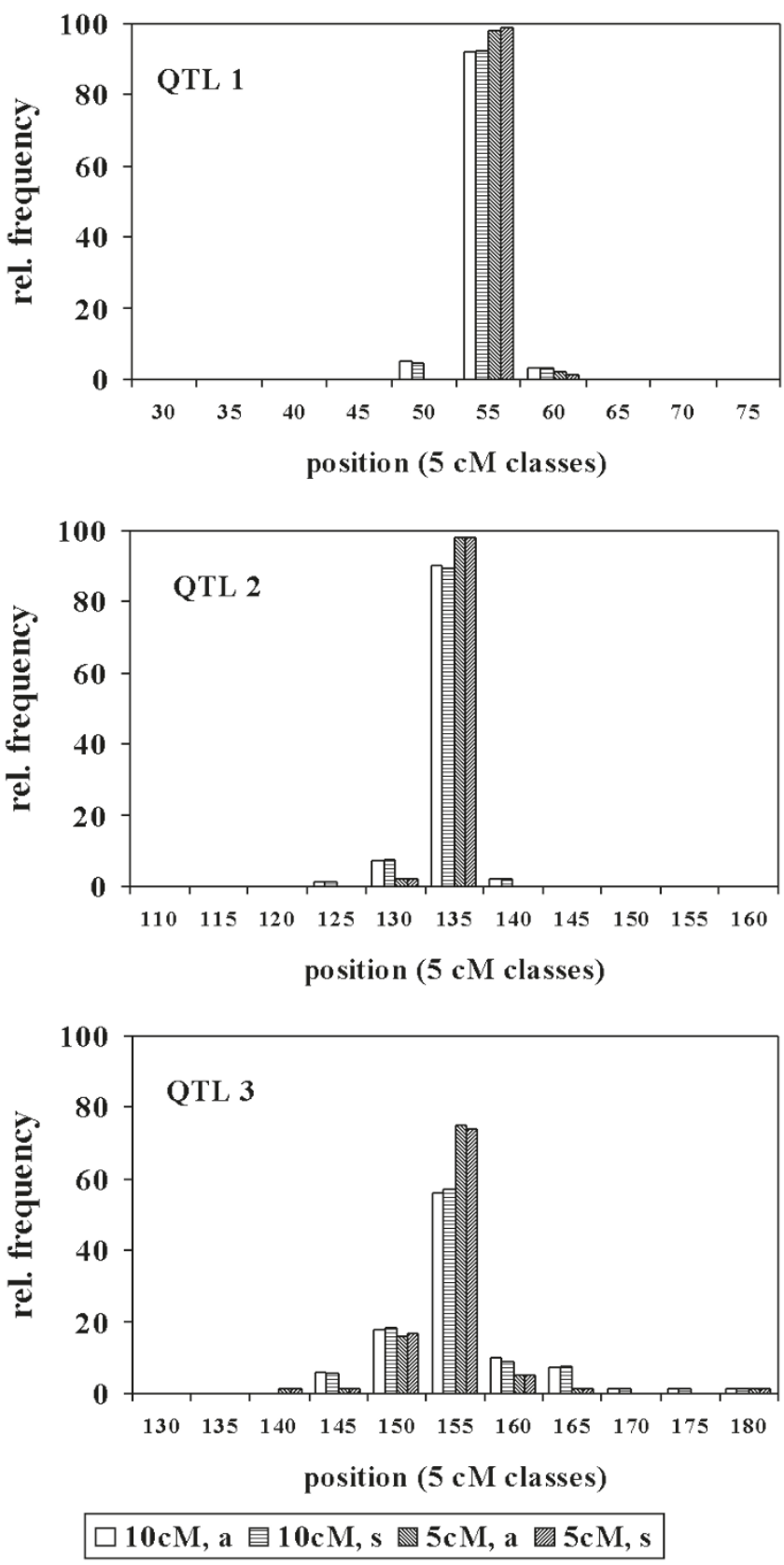

Figure 4. Distribution of the QTL position estimates for model 2 (rounded to the nearest $5 \mathrm{cM}$ value) and a relative QTL variance of 0.5 (a: all replicates $(N=100)$; $\mathrm{s}$ : based on the most stringent criterion (Bonferroni argument); no. of replicates see Tab. I). 


\subsection{Effect estimates in model 1}

The mean estimated additive QTL effects were close to the true effects (Tab. III) except for low QTL variance (0.25) and wide marker interval size $(10 \mathrm{cM})$. The empirical standard deviations of the additive QTL effect estimates were rather large. With a relative QTL variance of 0.25 and setting the true QTL effect equal to one, they ranged from 0.515 to 0.708 (marker interval of $10 \mathrm{cM}$ ) and from 0.197 to 0.279 (marker interval of $5 \mathrm{cM}$ ), respectively. The respective values for the QTL variance of 0.50 were 0.120 to 0.214 (marker interval of $10 \mathrm{cM}$ ) and 0.114 to 0.158 (marker interval of $5 \mathrm{cM}$ ). It is apparent that the reduction of the marker interval from $10 \mathrm{cM}$ to $5 \mathrm{cM}$ led to a remarkable improvement of the QTL effect estimates. Because QTL 2 and QTL 3 are in a relatively close neighborhood, the estimated effects of QTL 2 and QTL 3 were highly negatively correlated. The correlation coefficients were $-0.82,-0.82$ and -0.81 for the marker interval of $10 \mathrm{cM}$ and the relative QTL variance of $0.25,0.50$ and 0.75 , respectively, and $-0.70,-0.71$ and -0.70 for the marker interval of $5 \mathrm{cM}$.

Although the means of the estimated asymptotic standard deviation of the QTL effect estimates were generally smaller than the empirical standard deviations (Tab. III), they were close to the empirical standard deviations except for the case with a relative QTL variance of 0.25 and marker interval of $10 \mathrm{cM}$. The estimated asymptotic standard deviation also reflected the smaller empirical standard deviation when increasing the marker density from $10 \mathrm{cM}$ to $5 \mathrm{cM}$. For the relative QTL variance of 0.25 as well as for 0.50 and the larger marker interval of $10 \mathrm{cM}$ the estimated asymptotic standard deviation of the effect estimates showed a relatively large variation over the replicates.

\subsection{Effect estimates in model 2}

The standard deviations of the estimates of the additive QTL effect from model 2 (Tab. III) were in general larger as compared to the results from model 1 . There were evident differences in the accuracy of the estimates between the three QTL. The additive genetic effect of QTL 1 was more accurately estimated than the effects of QTL 2 and QTL 3. The denser marker map led to obviously more accurate estimates. The asymptotic standard deviation of the additive, dominance and epistatic effects did not reflect the empirical standard deviations of the estimates very well, when the relative QTL variance was smaller/equal to 0.50 (Tabs. III and IV). This was also reflected by the empirical coverage probabilities, which were smaller than the nominal confidence interval using the asymptotic statistical theory (Tab. V). 
Table III. Means and empirical standard deviations of additive QTL effect estimates over 100 replicates of simulation models 1 and 2 and means and standard deviations of the estimated asymptotic standard deviation $\left(\mathrm{R}^{2}\right.$, a, s: see Tab. II).

\begin{tabular}{|c|c|c|c|c|c|c|c|c|c|}
\hline & \multirow[t]{2}{*}{$\mathrm{R}^{2}$} & \multirow{2}{*}{$\begin{array}{l}\text { Marker- } \\
\text { interval }\end{array}$} & & \multicolumn{3}{|c|}{ Model 1} & \multicolumn{3}{|c|}{ Model 2} \\
\hline & & & & QTL1 & QTL2 & QTL3 & QTL1 & QTL2 & QTL3 \\
\hline \multirow{11}{*}{$\begin{array}{l}\text { True value } \\
\text { mean }\end{array}$} & & & & 1 & 1 & 1 & 1 & 1 & 1 \\
\hline & 0.25 & $10 \mathrm{cM}$ & $\mathrm{a}$ & 0.835 & 1.247 & 0.873 & 0.914 & 0.840 & 1.159 \\
\hline & 0.25 & $10 \mathrm{cM}$ & s & 0.935 & 1.300 & 0.770 & 0.994 & 0.692 & 1.229 \\
\hline & 0.25 & $5 \mathrm{cM}$ & $\mathrm{a}$ & 0.988 & 1.001 & 1.036 & 0.990 & 0.865 & 1.090 \\
\hline & 0.25 & $5 \mathrm{cM}$ & s & 0.993 & 1.098 & 1.002 & 0.983 & 0.717 & 1.235 \\
\hline & 0.50 & $10 \mathrm{cM}$ & $\mathrm{a}$ & 0.987 & 1.025 & 0.971 & 0.986 & 0.948 & 1.021 \\
\hline & 0.50 & $10 \mathrm{cM}$ & s & 0.987 & 1.025 & 0.971 & 0.995 & 0.929 & 1.044 \\
\hline & 0.50 & $5 \mathrm{cM}$ & $\mathrm{a}$ & 0.994 & 0.994 & 1.006 & 0.996 & 0.961 & 1.012 \\
\hline & 0.50 & $5 \mathrm{cM}$ & $\mathrm{s}$ & 0.994 & 0.994 & 1.006 & 1.002 & 0.954 & 1.027 \\
\hline & 0.75 & $10 \mathrm{cM}$ & $\mathrm{a}, \mathrm{s}$ & 0.990 & 0.994 & 0.995 & 0.989 & 0.977 & 1.000 \\
\hline & 0.75 & $5 \mathrm{cM}$ & $\mathrm{a}, \mathrm{s}$ & 0.997 & 0.996 & 1.001 & 0.995 & 0.985 & 0.998 \\
\hline \multirow[t]{10}{*}{ SD } & 0.25 & $10 \mathrm{cM}$ & $\mathrm{a}$ & 0.515 & 0.547 & 0.708 & 0.401 & 0.656 & 0.533 \\
\hline & 0.25 & $10 \mathrm{cM}$ & s & 0.311 & 0.557 & 0.741 & 0.250 & 0.526 & 0.435 \\
\hline & 0.25 & $5 \mathrm{cM}$ & $\mathrm{a}$ & 0.197 & 0.279 & 0.278 & 0.304 & 0.518 & 0.462 \\
\hline & 0.25 & $5 \mathrm{cM}$ & $\mathrm{s}$ & 0.174 & 0.199 & 0.180 & 0.271 & 0.471 & 0.380 \\
\hline & 0.50 & $10 \mathrm{cM}$ & $\mathrm{a}$ & 0.120 & 0.214 & 0.193 & 0.152 & 0.309 & 0.297 \\
\hline & 0.50 & $10 \mathrm{cM}$ & s & 0.120 & 0.214 & 0.193 & 0.150 & 0.304 & 0.284 \\
\hline & 0.50 & $5 \mathrm{cM}$ & $\mathrm{a}$ & 0.114 & 0.165 & 0.158 & 0.143 & 0.243 & 0.247 \\
\hline & 0.50 & $5 \mathrm{cM}$ & $\mathrm{s}$ & 0.114 & 0.165 & 0.158 & 0.138 & 0.237 & 0.238 \\
\hline & 0.75 & $10 \mathrm{cM}$ & $\mathrm{a}, \mathrm{s}$ & 0.072 & 0.120 & 0.109 & 0.091 & 0.152 & 0.155 \\
\hline & 0.75 & $5 \mathrm{cM}$ & $\mathrm{a}, \mathrm{s}$ & 0.069 & 0.092 & 0.096 & 0.086 & 0.130 & 0.129 \\
\hline \multirow{10}{*}{$\begin{array}{l}\text { Mean of estim. } \\
\text { asymp. SD }\end{array}$} & 0.25 & $10 \mathrm{cM}$ & $\mathrm{a}$ & 0.228 & 0.329 & 0.287 & 0.294 & 0.409 & 0.370 \\
\hline & 0.25 & $10 \mathrm{cM}$ & $\mathrm{s}$ & 0.188 & 0.302 & 0.298 & 0.274 & 0.408 & 0.390 \\
\hline & 0.25 & $5 \mathrm{cM}$ & $\mathrm{a}$ & 0.183 & 0.256 & 0.247 & 0.262 & 0.362 & 0.350 \\
\hline & 0.25 & $5 \mathrm{cM}$ & $\mathrm{s}$ & 0.181 & 0.252 & 0.248 & 0.264 & 0.350 & 0.342 \\
\hline & 0.50 & $10 \mathrm{cM}$ & $\mathrm{a}$ & 0.110 & 0.183 & 0.181 & 0.156 & 0.255 & 0.250 \\
\hline & 0.50 & $10 \mathrm{cM}$ & s & 0.110 & 0.183 & 0.181 & 0.156 & 0.245 & 0.240 \\
\hline & 0.50 & $5 \mathrm{cM}$ & $\mathrm{a}$ & 0.106 & 0.152 & 0.150 & 0.149 & 0.211 & 0.208 \\
\hline & 0.50 & $5 \mathrm{cM}$ & $\mathrm{s}$ & 0.106 & 0.152 & 0.150 & 0.149 & 0.211 & 0.207 \\
\hline & 0.75 & $10 \mathrm{cM}$ & $\mathrm{a}, \mathrm{s}$ & 0.065 & 0.104 & 0.103 & 0.092 & 0.143 & 0.142 \\
\hline & 0.75 & $5 \mathrm{cM}$ & $\mathrm{a}, \mathrm{s}$ & 0.062 & 0.089 & 0.088 & 0.086 & 0.125 & 0.123 \\
\hline \multirow{10}{*}{$\begin{array}{l}\text { SD of estim. } \\
\text { asymp. SD }\end{array}$} & 0.25 & $10 \mathrm{cM}$ & $\mathrm{a}$ & 0.376 & 0.389 & 0.156 & 0.130 & 0.152 & 0.112 \\
\hline & 0.25 & $10 \mathrm{cM}$ & $\mathrm{s}$ & 0.009 & 0.130 & 0.131 & 0.027 & 0.109 & 0.109 \\
\hline & 0.25 & $5 \mathrm{cM}$ & $\mathrm{a}$ & 0.025 & 0.036 & 0.038 & 0.029 & 0.100 & 0.098 \\
\hline & 0.25 & $5 \mathrm{cM}$ & $\mathrm{s}$ & 0.009 & 0.029 & 0.029 & 0.033 & 0.072 & 0.051 \\
\hline & 0.50 & $10 \mathrm{cM}$ & $\mathrm{a}$ & 0.005 & 0.038 & 0.040 & 0.007 & 0.110 & 0.107 \\
\hline & 0.50 & $10 \mathrm{cM}$ & $\mathrm{s}$ & 0.005 & 0.038 & 0.040 & 0.007 & 0.038 & 0.034 \\
\hline & 0.50 & $5 \mathrm{cM}$ & $\mathrm{a}$ & 0.004 & 0.010 & 0.011 & 0.007 & 0.038 & 0.037 \\
\hline & 0.50 & $5 \mathrm{cM}$ & $\mathrm{s}$ & 0.004 & 0.010 & 0.011 & 0.007 & 0.039 & 0.038 \\
\hline & 0.75 & $10 \mathrm{cM}$ & $\mathrm{a}, \mathrm{s}$ & 0.003 & 0.008 & 0.009 & 0.004 & 0.017 & 0.017 \\
\hline & 0.75 & $5 \mathrm{cM}$ & $\mathrm{a}, \mathrm{s}$ & 0.002 & 0.008 & 0.009 & 0.009 & 0.010 & 0.010 \\
\hline
\end{tabular}


Table IV. Means and empirical standard deviations of dominance and epistatic effect estimates over 100 replicates of simulation model 2 and means and standard deviations of the estimated asymptotic standard deviation $\left(\mathrm{R}^{2}\right.$, a, s: see Tab. II).

\begin{tabular}{|c|c|c|c|c|c|c|c|c|c|}
\hline & \multirow[t]{2}{*}{$\mathrm{R}^{2}$} & \multirow{2}{*}{$\begin{array}{l}\text { Marker- } \\
\text { interval }\end{array}$} & & \multicolumn{3}{|c|}{ Dominance effect } & \multicolumn{3}{|c|}{ Epistatic effect } \\
\hline & & & & QTL1 & QTL2 & QTL3 & QTL1/2 & $1 / 3$ & $2 / 3$ \\
\hline \multirow{11}{*}{$\begin{array}{l}\text { True value } \\
\text { mean }\end{array}$} & & & & 0 & 0 & 0.5 & -3.0 & 0 & 0 \\
\hline & 0.25 & $10 \mathrm{cM}$ & $\mathrm{a}$ & 0.003 & 0.083 & 0.494 & -2.312 & -0.531 & -0.005 \\
\hline & 0.25 & $10 \mathrm{cM}$ & $\mathrm{s}$ & -0.100 & -0.101 & 0.572 & -2.802 & -0.266 & -0.011 \\
\hline & 0.25 & $5 \mathrm{cM}$ & $\mathrm{a}$ & -0.005 & -0.035 & 0.483 & -2.702 & -0.307 & -0.052 \\
\hline & 0.25 & $5 \mathrm{cM}$ & s & -0.062 & -0.161 & 0.589 & -2.764 & -0.322 & -0.052 \\
\hline & 0.50 & $10 \mathrm{cM}$ & $\mathrm{a}$ & -0.004 & -0.050 & 0.521 & -2.887 & -0.099 & -0.012 \\
\hline & 0.50 & $10 \mathrm{cM}$ & s & 0.001 & -0.053 & 0.536 & -2.881 & -0.106 & -0.007 \\
\hline & 0.50 & $5 \mathrm{cM}$ & $\mathrm{a}$ & -0.000 & -0.064 & 0.510 & -2.937 & -0.077 & -0.30 \\
\hline & 0.50 & $5 \mathrm{cM}$ & $\mathrm{s}$ & 0.003 & -0.056 & 0.503 & -2.930 & -0.089 & -0.036 \\
\hline & 0.75 & $10 \mathrm{cM}$ & $\mathrm{a}, \mathrm{s}$ & -0.003 & -0.024 & 0.519 & -2.946 & -0.041 & 0.019 \\
\hline & 0.75 & $5 \mathrm{cM}$ & $\mathrm{a}, \mathrm{s}$ & -0.005 & -0.028 & 0.505 & -2.960 & -0.050 & -0.001 \\
\hline \multirow[t]{10}{*}{ SD } & 0.25 & $10 \mathrm{cM}$ & $\mathrm{a}$ & 0.629 & 0.876 & 0.683 & 1.747 & 1.414 & 0.095 \\
\hline & 0.25 & $10 \mathrm{cM}$ & $\mathrm{s}$ & 0.476 & 0.685 & 0.681 & 1.147 & 1.187 & 0.927 \\
\hline & 0.25 & $5 \mathrm{cM}$ & $\mathrm{a}$ & 0.450 & 0.780 & 0.720 & 1.023 & 0.874 & 1.040 \\
\hline & 0.25 & $5 \mathrm{cM}$ & s & 0.461 & 0.641 & 0.608 & 0.940 & 0.896 & 0.910 \\
\hline & 0.50 & $10 \mathrm{cM}$ & $\mathrm{a}$ & 0.244 & 0.370 & 0.401 & 0.355 & 0.405 & 0.527 \\
\hline & 0.50 & $10 \mathrm{cM}$ & s & 0.247 & 0.367 & 0.395 & 0.350 & 0.402 & 0.521 \\
\hline & 0.50 & $5 \mathrm{cM}$ & $\mathrm{a}$ & 0.227 & 0.326 & 0.386 & 0.322 & 0.313 & 0.494 \\
\hline & 0.50 & $5 \mathrm{cM}$ & $\mathrm{s}$ & 0.230 & 0.322 & 0.394 & 0.314 & 0.306 & 0.489 \\
\hline & 0.75 & $10 \mathrm{cM}$ & $\mathrm{a}, \mathrm{s}$ & 0.136 & 0.195 & 0.241 & 0.183 & 0.201 & 0.315 \\
\hline & 0.75 & $5 \mathrm{cM}$ & $\mathrm{a}, \mathrm{s}$ & 0.129 & 0.178 & 0.215 & 0.183 & 0.174 & 0.268 \\
\hline \multirow{10}{*}{$\begin{array}{l}\text { Mean of estim. } \\
\text { asymp. SD }\end{array}$} & 0.25 & $10 \mathrm{cM}$ & $\mathrm{a}$ & 0.416 & 0.572 & 0.568 & 0.629 & 0.616 & 0.712 \\
\hline & 0.25 & $10 \mathrm{cM}$ & s & 0.400 & 0.540 & 0.573 & 0.592 & 0.586 & 0.721 \\
\hline & 0.25 & $5 \mathrm{cM}$ & $\mathrm{a}$ & 0.337 & 0.524 & 0.515 & 0.549 & 0.536 & 0.639 \\
\hline & 0.25 & $5 \mathrm{cM}$ & s & 0.378 & 0.529 & 0.514 & 0.537 & 0.522 & 0.633 \\
\hline & 0.50 & $10 \mathrm{cM}$ & $\mathrm{a}$ & 0.225 & 0.349 & 0.359 & 0.354 & 0.366 & 0.456 \\
\hline & 0.50 & $10 \mathrm{cM}$ & s & 0.224 & 0.346 & 0.352 & 0.349 & 0.359 & 0.451 \\
\hline & 0.50 & $5 \mathrm{cM}$ & $\mathrm{a}$ & 0.212 & 0.311 & 0.301 & 0.310 & 0.315 & 0.387 \\
\hline & 0.50 & $5 \mathrm{cM}$ & $\mathrm{s}$ & 0.212 & 0.311 & 0.299 & 0.309 & 0.312 & 0.385 \\
\hline & 0.75 & $10 \mathrm{cM}$ & $\mathrm{a}, \mathrm{s}$ & 0.130 & 0.201 & 0.205 & 0.195 & 0.203 & 0.264 \\
\hline & 0.75 & $5 \mathrm{cM}$ & $\mathrm{a}, \mathrm{s}$ & 0.123 & 0.176 & 0.174 & 0.175 & 0.176 & 0.220 \\
\hline \multirow{10}{*}{$\begin{array}{l}\text { SD of estim. } \\
\text { asymp. SD }\end{array}$} & 0.25 & $10 \mathrm{cM}$ & $\mathrm{a}$ & 0.133 & 0.222 & 0.245 & 0.294 & 0.325 & 0.382 \\
\hline & 0.25 & $10 \mathrm{cM}$ & s & 0.041 & 0.119 & 0.162 & 0.206 & 0.187 & 0.293 \\
\hline & 0.25 & $5 \mathrm{cM}$ & $\mathrm{a}$ & 0.037 & 0.152 & 0.148 & 0.161 & 0.157 & 0.229 \\
\hline & 0.25 & $5 \mathrm{cM}$ & s & 0.041 & 0.097 & 0.102 & 0.090 & 0.086 & 0.159 \\
\hline & 0.50 & $10 \mathrm{cM}$ & $\mathrm{a}$ & 0.009 & 0.053 & 0.073 & 0.074 & 0.081 & 0.100 \\
\hline & 0.50 & $10 \mathrm{cM}$ & s & 0.009 & 0.048 & 0.057 & 0.060 & 0.065 & 0.093 \\
\hline & 0.50 & $5 \mathrm{cM}$ & $\mathrm{a}$ & 0.011 & 0.055 & 0.058 & 0.043 & 0.050 & 0.086 \\
\hline & 0.50 & $5 \mathrm{cM}$ & $\mathrm{s}$ & 0.008 & 0.046 & 0.052 & 0.042 & 0.044 & 0.086 \\
\hline & 0.75 & $10 \mathrm{cM}$ & $\mathrm{a}, \mathrm{s}$ & 0.005 & 0.023 & 0.027 & 0.021 & 0.023 & 0.051 \\
\hline & 0.75 & $5 \mathrm{cM}$ & $\mathrm{a}, \mathrm{s}$ & 0.004 & 0.027 & 0.028 & 0.016 & 0.023 & 0.036 \\
\hline
\end{tabular}


Table V. Empirical coverage probability (in \%) of nominal 95\%-confidence intervals using asymptotic statistical theory $\left(\mathrm{R}^{2}\right.$, a, s: see Tab. II).

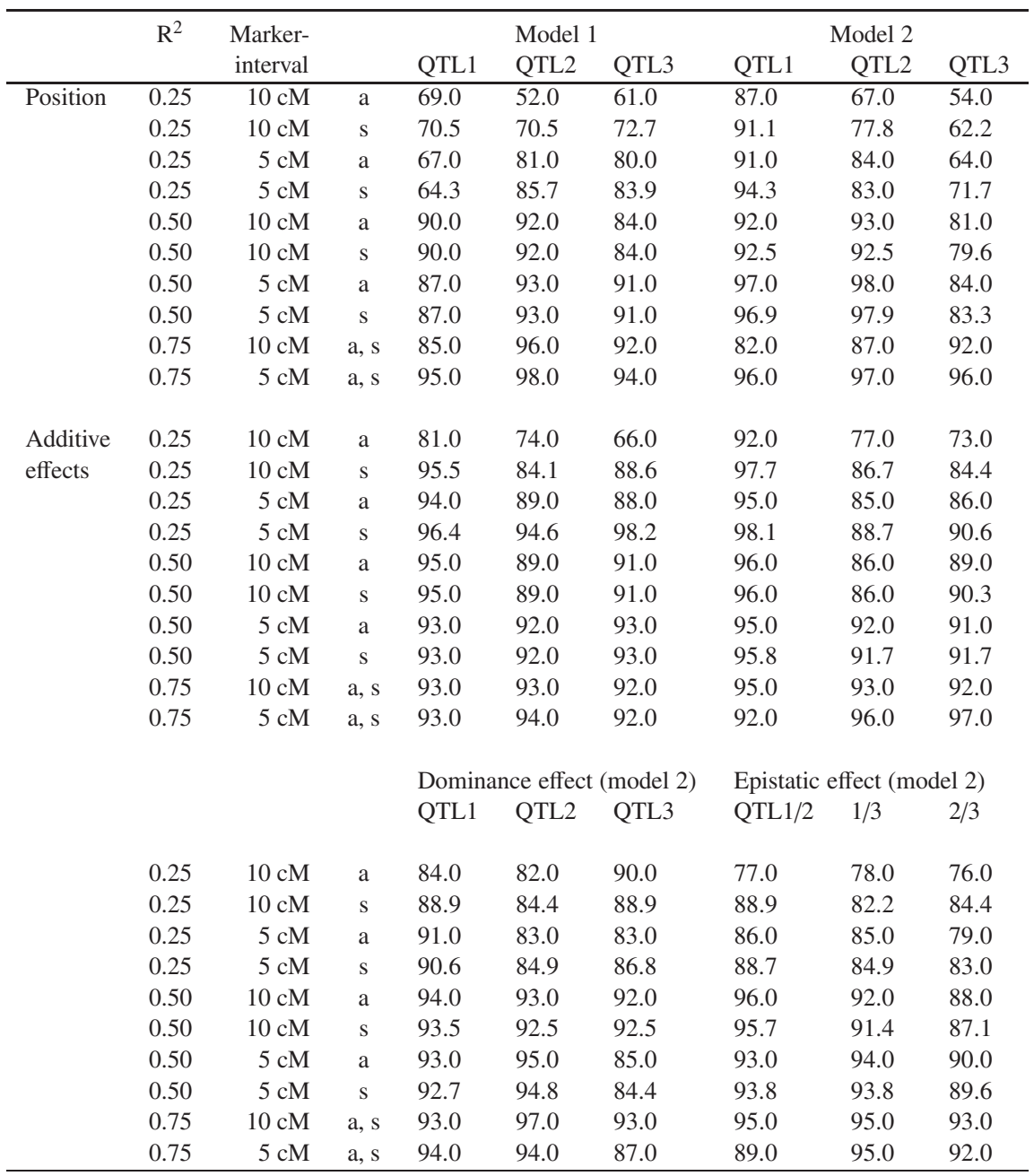

As can be seen from Table IV, the empirical standard deviations of the dominance effect estimates were generally larger than for the additive effects and resulted in rather high values. Even with a large relative QTL variance of 0.75 and a dense marker map of $5 \mathrm{cM}$, the true parameter value $d_{3}$ being 0.50 , the standard deviation of the estimate was 0.215 . The difficulties in estimating the epistatic effects were even greater as can be seen from the standard deviations of the estimates in Table IV. 


\section{DISCUSSION AND IMPLICATIONS}

A number of recently published results from QTL analyses using large populations or from gene expression studies (e.g. [29]) raise doubts on the validity of the assumption of a few QTL with large effects segregating for complex traits. Openshaw and Frascaroli [23] for example found in their mapping study 28 and 36 QTL for grain yield and plant height, respectively. Despite this large number of QTL, they explained only 54 and $60 \%$ of the genotypic variance, respectively. In the study by Kao et al. [14], analyzing the traits cone number, tree diameter and branch quality in a sample of 134 radiata pine 7 , 6 and 5 QTL were detected for the 3 traits, respectively using multiple interval mapping. The detected QTL individually contributed from $\sim 1$ to $27 \%$ of the total genetic variation. Significant epistasis between four pairs of QTL in 2 traits was detected, and the four pairs of QTL contributed 10.4 and $14.1 \%$ of the total genetic variation. Together, the QTL explained 56, 52 and 38\% of the phenotypic variances for the 3 traits, respectively. The multiple interval mapping analysis indicated strong repulsion linkage effects of closely linked QTL, which was missed by the composite interval mapping analysis. So, identifying multiple QTL in a linkage group and quantifying their effects while taking epistatic effects into account is an important task.

The results of our simulation study show, that multiple interval mapping is able to locate multiple QTL in a linkage group and to quantify their effects. But our simulation study also shows that the multi-dimensional likelihood landscape, especially for the marker interval size of $10 \mathrm{cM}$ and/or lower QTL variances often had several local peaks and often there were plateaus around those peaks or the peaks were connected by ridges. This resulted in rather large standard errors of the estimates and the conclusion therefore must be that with an increasing complexity of the genetic model, the demands on sample size and marker density also increase. Thus, in comparison with a simple monogenetic background, QTL detection (e.g. $[12,16,27])$ and a reliable and accurate estimation of QTL positions and QTL effects of multiple QTL in a linkage group requires much more information from the data. In the scenarios we studied, the identification of the QTL was the most easiest among the following tasks: the identification of the number of the QTL, localization of the QTL and estimation of the QTL effects. The empirical standard deviations of the genetic effect estimates were generally large. They were the largest for the epistatic effects and those of the dominance effects were larger than those of the additive effects.

For (single) interval mapping, a marker density of $10 \mathrm{cM}$ is generally considered as sufficient. Using analytical results, Piepho [24] showed for the case 
of interval mapping in a backcross population, that the power of QTL detection and the standard errors of genetic effect estimates are little affected by an increase of marker density beyond $10 \mathrm{cM}$. Dupuis and Siegmund [9] found that when using a backcross or intercross, intermarker distances up to $\sim 10 \mathrm{cM}$ are almost as powerful as continuously distributed markers. In Dupuis and Siegmund [9], a detailed discussion on statistical problems encountered with the computation of confidence intervals for QTL position and effect estimates in the interval mapping case, i.e., 1 QTL case, can be found. They found that support regions and Bayesian credible sets seem roughly comparable in large samples, but the coverage probability of the support method was more robust to changes in the sample size. Both methods were better than the likelihood ratio method, which often had a coverage probability substantially smaller than the nominal level, except for the case of dense markers. The size of a confidence region depends on the noncentrality parameter and the density of the markers in the neighborhood of the QTL. When the noncentrality parameter was $\sim 5$, which provides a power of $\sim 0.9$ for QTL detection, little was gained by having markers more closely spaced than $\sim 10 \mathrm{cM}$. Also Visscher et al. [28] found that marker spacing only has a small effect on the average empirical confidence interval for QTL location.

For multiple interval mapping and linked QTL, we found in this study that the reduction of the marker interval size from $10 \mathrm{cM}$ to $5 \mathrm{cM}$ led to a significantly higher power in QTL detection. We also found the reduction of the marker interval size from $10 \mathrm{cM}$ to $5 \mathrm{cM}$ led to a remarkable improvement of the QTL position as well as the QTL effect estimates. There were no major differences in the estimates between the marker interval of 5 and $10 \mathrm{cM}$ in all the replications. But for the replicates with the largest values of the mean difference between the QTL position estimates from the 2 marker interval sizes $(m d)$, it was found that the likelihood surface often showed several local maxima of almost equal likelihood values when the marker distance was $10 \mathrm{cM}$ and became more "peaked" if the marker distance was $5 \mathrm{cM}$.

In our study, the asymptotic standard deviation of the position estimates was not a good criterion for the accuracy of the position estimates and may be much too optimistic in many cases. The observation that QTL position estimates close to the markers led to an asymptotic standard deviation sensitive to modifications in the positions used for these calculations confirmed the problematic nature of the asymptotic standard deviation. Confidence intervals based on the asymptotic statistical theory had a clearly smaller empirical coverage probability as compared to the nominal confidence interval. The asymptotic standard deviation of the QTL effects was not in good accordance 
with the empirical standard deviations, when the relative QTL variance was smaller/equal to 0.50 . Thus, our findings nicely reflect the consequences from the Rao-Cramer inequality, which states that under some regularity conditions and if there is an unbiased estimator, the asymptotic standard deviation from Fisher information is just the lower boundary for the standard deviation of the estimate. A further aspect is the localization of QTL in the wrong marker interval. Accordingly in these cases the empirical coverage probability was also influenced.

To our knowledge there are presently only 2 computer programs available for multiple interval mapping strategies. The program of Nakamichi et al. [22] uses a moment method to remove the effects of other QTL and does not allow the analysis of epistasis. Although the authors state that the evaluation of the accuracy of the estimation is an important issue, their program does not provide any information on the accuracy of the estimates. The MImapqtl program of the QTL Cartographer [2] does not provide results on the accuracy of the position estimates, but the asymptotic standard errors of effect estimates can be computed. From our results, there is the conclusion that one has to be careful in relying on the asymptotic standard errors of the effect estimates and that there are very common situations where the standard errors of the additive genetic effect estimates and even more the standard errors of the nonadditive genetic effect estimates are (very) inaccurate. Also in the F2 QTL analysis servlet for 2-QTL analyses by Seaton et al. [26] using regression interval mapping, no results on the accuracy of the position estimates and only standard errors of effect estimates are provided.

Currently, we are extending our investigations to assess the usefulness of several resampling methods for computing standard errors of position and effect estimates and to construct confidence intervals in multiple interval mapping models. Carlborg et al. [3] called multiple interval mapping a quasisimultaneous QTL mapping method, because in a simultaneous search for multiple QTL, methods based on enumerative search methods rapidly become computationally intractable as the number of QTL in the model increases. Although the use of genetic algorithms may reduce the computational burden, it seems to be intractable to analyze for example 1000 sample sets as would be required for bootstrapping or permutation approaches to obtain an empirical distribution of the estimates for a specific model with several QTL.

\section{REFERENCES}

[1] Akaike H., A new look at the statistical model identification, IEEE Trans. Automat. Control 19 (1974) 716-723. 
[2] Basten C.J., Weir B.S., Zeng Z.-B., QTL Cartographer, A reference manual and tutorial for QTL mapping, Program in Statistical Genetics, North Carolina State University, Raleigh, USA, 2001.

[3] Carlborg Ö., Andersson L., Kinghorn B., The use of a genetic algorithm for simultaneous mapping of multiple interacting quantitative trait loci, Genetics 155 (2000) 2003-2010.

[4] Casella G., Berger R.L., Statistical Inference, Pacific Grove California: Brooks/Cole, 1990.

[5] Cockerham C.C., An extension of the concept of partitioning hereditary variance for analysis of covariances among relatives when epistasis is present, Genetics 39 (1954) 859-882.

[6] Darvasi A., Soller M., A simple method to calculate resolving power and confidence intervals of QTL map location, Behav. Genet. 27 (1997) 125-132.

[7] Darvasi A., Weinreb A., Minke V., Weller J.I., Soller M., Detecting markerQTL linkage and estimating QTL gene effect and map location using a saturated genetic map, Genetics 134 (1993) 943-951.

[8] Dempster A.P., Laird N.M., Rubin D.B., Maximum likelihood from incomplete data via the EM algorithm, J. Royal Stat. Soc. 39 (1977) 1-38.

[9] Dupuis J., Siegmund D., Statistical methods for mapping quantitative trait loci from a dense set of markers, Genetics 151 (1999) 373-386.

[10] Haley C.S., Knott S.A., A simple regression method for mapping quantitative trait in line crosses using flanking markers, Heredity 69 (1992) 315-324.

[11] Jansen R.C., Interval mapping of multiple quantitative trait loci, Genetics 135 (1993) 205-211.

[12] Kao C.-H., On the differences between maximum likelihood and regression interval mapping in the analysis of quantitative trait loci, Genetics 156 (2000) $855-865$.

[13] Kao C.-H., Zeng Z.-B., General formulas for obtaining the MLEs and the asymptotic variance-covariance matrix in mapping quantitative trait loci when using the EM algorithm, Biometrics 53 (1997) 653-665.

[14] Kao C.-H., Zeng Z.-B., Teasdale R.D., Multiple interval mapping for quantitative trait loci, Genetics 152 (1999) 1203-1216.

[15] Lander E.S., Botstein D., Mapping Mendelian factors underlying quantitative traits using RFLP linkage maps, Genetics 121 (1989) 185-199.

[16] Lander E.S., Kruglyak V., Genetic dissection of complex traits: guidelines for interpreting and reporting linkage results, Nat. Genet. 11 (1995) 241-247.

[17] Lebreton C.M., Visscher P.M., Empirical nonparametric bootstrap strategies in quantitative trait loci mapping: conditioning on the genetic model, Genetics 148 (1998) 525-535.

[18] Little R.J.A., Rubin D.B., Statistical analysis with missing data, John Wiley, New York, 1987.

[19] Liu Y., Zeng Z.-B., A general mixture model approach for mapping quantitative trait loci from diverse cross designs involving multiple inbred lines, Genet. Res. Camb. 75 (2000) 345-355.

[20] Louis T.A., Finding the observed information matrix when using the EM algorithm, J. Royal Stat. Soc., Series B 44 (1982) 226-233. 
[21] Mangin B., Goffinet B., Rebai A., Constructing confidence intervals for QTL location, Genetics 138 (1994) 1301-1308.

[22] Nakamichi R., Ukai Y., Kishino H., Detection of closely linked multiple quantitative trait loci using a genetic algorithm, Genetics 158 (2001) 463-475.

[23] Openshaw S., Frascaroli E., QTL detection and marker-assisted selection for complex traits in maize, in: 52nd Annual Corn and Sorghum Industry Research Conference, ASTA, Washington, DC (1997) pp. 44-53.

[24] Piepho H.P., Optimal marker density for interval mapping in a backcross population, Heredity 84 (2000) 437-440.

[25] Schwarz G., Estimating the dimension of a model, Ann. Stat. 6 (1978) 461-464.

[26] Seaton G., Haley C., Knott S., Kearsey M., Visscher P., QTL express, http://qtl.cap.ed.ac.uk, 2002.

[27] Soller M., Genizi A., The efficiency of experimental designs for the detection of linkage between a marker locus and a locus affecting a quantitative trait in segregating populations, Biometrics 34 (1978) 47-55.

[28] Visscher P.M., Thompson R., Haley C.S., Confidence intervals in QTL mapping by bootstrapping, Genetics 143 (1996) 1013-1020.

[29] Wolfinger R.D., Gibson G., Wolfinger E.D., Bennett L., Hamadeh H., Bushel P., Afshari C., Paules R.S., Assessing gene significance from cDNA microarray expression data via mixed models, J. Comp. Biol. 8 (2001) 625-637.

[30] Zeng Z.-B., Theoretical basis for separation of multiple linked gene effects in mapping of quantitative trait loci, Proc. Natl. Acad. Sci. 90 (1993) 10972-10976.

[31] Zeng Z.-B., Precision mapping of quantitative trait loci, Genetics 136 (1994) 1457-1468.

[32] Zeng Z.-B., Kao C.-H., Basten C.J., Estimating the genetic architecture of quantitative traits, Genet. Res. Camb. 74 (1999) 279-289.

To access this journal online: www.edpsciences.org 